\title{
Mucosal function in rat jejunum and ileum is altered by induction of colitis
}

\author{
EINAT AMIT-ROMACH ${ }^{1,2}$, RAM REIFEN $^{2}$ and ZEHAVA UNI $^{1}$ \\ ${ }^{1}$ Department of Animal Science and ${ }^{2}$ The School of Nutritional Sciences, The Faculty of Agricultural, Food \\ and Environmental Quality Sciences, The Hebrew University of Jerusalem, Rehovot 76100, Israel
}

Received March 22, 2006; Accepted May 18, 2006

\begin{abstract}
Many studies dealing with trinitrobenzene sulfonic acid (TNBS) colitis in rats have been carried out refering only to the colon. In humans, ulcerative colitis (UC) can extend a variable distance into the terminal ileum in a phenomenon known as backwash ileitis (BWI). The aim of this study was therefore to examine the effect of TNBSinduced colitis on different aspects of the rat ileum and jejunum. We hypothesized that TNBS administration would lead to a systemic influence on the small intestine. Rats were induced colitis by administration of $0.25 \mathrm{ml}$ of 2,4,6-trinitrobenzene sulfonic acid and $72 \mathrm{~h}$ after colitis induction animals were sacrificed. Segments were taken of the colon, ileum and jejunum. In addition to mucin mRNA expression, morphological changes were observed in the jejunum and ileum. We examined the mRNA expression and biochemical activity of brush border enzyme, sucrase iso-maltase and aminopeptidase, in all three segments. The villous surface area of colitis-induced rats was smaller in jejunum and ileum compared to control. In the jejunum of TNBS-induced rats, goblet-cell volume increased and their density decreased. The relative amount of MUC2 mRNA decreased in the jejunum, ileum and colon of colitis rat. However, MUC3 mRNA expression increased in the ileum and colon of these rats. Sucrase isomaltase expression and activity decreased in the ileum of TNBS-induced rats, while aminopeptidase activity was lower in the jejunum. These observations suggest that intrarectal administration of TNBS to rats influences not only their colon and terminal ileum, but also the proximal ileum and jejunum. Involvement of the ileum and jejunum in TNBSinduced colitis may be related to the systemic reaction of the immune system and mucosa to colitis.
\end{abstract}

Correspondence to: Dr Zehava Uni, Department of Animal Science, Faculty of Agricultural, Food and Environmental Quality Sciences, The Hebrew University of Jerusalem, Rehovot 76100, Israel

E-mail: uni@agri.huji.ac.il

Key words: inflammatory bowel disease, rat model, gene expression, mucin, BBM enzyme

\section{Introduction}

Inflammatory bowel disease (IBD) (1) is a chronic and spontaneously relapsing disorder of the gastrointestinal (GI) tract, characterized by inflammation and tissue damage. The mechanism, as well as the exact etiology and pathogenesis of this disease are still not fully understood. Increasing experimental and clinical data suggest that the induction and pathogenesis of IBD is a multifactorial process involving interactions among genetic, immune and environmental factors $(2,3)$. Trinitrobenzene sulfonic acid (TNBS), one of the two models of colitis produced in rats that has received significant attention over the past few years. Intrarectal administration of TNBS (4) in the presence of a mucosal-barrier breaker such as ethanol produces acute and chronic colonic inflammation in unsensitized rats (5). Induction of colitis using TNBS is known to cause inflammation and tissue damage in the colon (6). The studies evolving from the use of this model in rats refer, therefore, only to the colon, rather than to the whole GI tract.

Ulcerative colitis (UC) is classified according to the location and extent of inflammation: ulcerative proctitis, for example, refers to inflammation that is limited to the rectum; proctosigmoiditis involves inflammation of the rectum and the sigmoid colon (a short segment of the colon contiguous to the rectum), and universal colitis refers to inflammation affecting the entire colon (right colon, left colon, transverse colon and rectum). When the entire colon is involved, UC can extend a variable distance into the terminal ileum in a phenomenon known as backwash ileitis (BWI) (7). BWI develops as a result of reflux of colonic contents into the ileum due to an incompetent or poorly functioning, and inflamed ileocecal valve (8), and features focal neutrophilic infiltrates of the superficial crypts and surface epithelium (9).

It is known that the integral intestine, characterized by intact villus structures, crypts and epithelium, comprises two major cell populations, the enterocytes and goblet cells. The proliferation, differentiation, and migration of these cells maintain the integrity of the continuously renewing intestinal epithelium (10-13). The digestive and absorptive functions are accomplished by brush-border-membrane (BBM) enzyme activities (14-16). Among these enzymes are sucrase-isomaltase (SI; EC 3.2.1.48), which catalyzes the hydrolysis of disaccharides into their constituent sugars (17-19), and amino-peptidase (LAP; EC 3.4.11.1), which catalyzes the 
hydrolysis of amino-acid residues at the amino terminus of peptide substrates $(13,20)$.

Mucus is an additional important factor in the GI tract. The epithelium of the GI tract is covered by a mucus layer that acts as a medium for protection, lubrication and transport between the luminal contents and the epithelial cells (12). Host commensal floras colonize the adherent mucus layer and, as a result, prevent the attachment of pathogenic organisms.

The mucus layer is composed predominantly of mucins, which are high-molecular-weight glycoproteins produced mainly by goblet cells. They are heavily glycosylated and are strongly charged, as a consequence of sialylation or sulfation. Two types of mucin can be found in the GI tract: the first is a gel-forming mucin, and the second, a membrane-bound one. The normal intestine is lined by mucus, whereas the ulcerated intestine is typically not (10). Therefore, changes in mucin dynamics would lead to reduced protection of the mucosa (11), and this would play an important role in the pathogenesis of UC (21).

We hypothesized that induction of TNBS colitis may affect the morphology and function of intestinal segments proximal to the colon. Accordingly, the aim of the present study was to examine the expression of functional intestinal genes such as SI, AP, MUC2 (a gel-forming mucin) and MUC3 (a membrane-bound mucin), and evaluate BBM enzymatic activity, in addition to recording morphometric measurements in the jejunal and ileal segments following induction of TNBS colitis.

\section{Materials and methods}

Animals. Male Wistar rats with an average weight of $375 \mathrm{~g}$ (range, 300-450 g) were obtained from the Harlan Laboratory at The Weizmann Institute of Science, Rehovot, Israel. They were housed in metal cages in a room with controlled temperature $\left(25 \pm 2^{\circ} \mathrm{C}\right)$, relative humidity $(65 \pm 5 \%)$ and light $(08: 00$ 20:00 h). Ethical approval was obtained for the study. The procedures were conducted in full compliance with the strict guidelines of the Hebrew University Policy on Animal Care and Use.

Induction of colitis and sample preparation. A modification of the procedure developed by Morris et al (5) was used to induce colitis. Rats were lightly anesthetized with ether and a rubber catheter (22) was inserted through the anal canal for a distance of $8 \mathrm{~cm}$ into the colon just proximal to the splenic flexure. Colitis was induced by the administration of $0.25 \mathrm{ml}$ 2,4,6-trinitrobenzene sulfonic acid (TNBS, $100 \mathrm{~g} / 1$ dissolved in 50\% ethanol); (Sigma Chemical Co., St. Louis, MO, USA). Animals from both control and treatment groups were sacrificed $72 \mathrm{~h}$ after colitis induction. Histological observations were carried out to ensure the existence of inflammation. Segments of the colon, ileum and jejunum were dissected, snap-frozen in liquid nitrogen and stored at $-80^{\circ} \mathrm{C}$ until analysis.

Total-RNA isolation. Briefly, total-RNA was isolated from the intestinal segments using TRI-Reagent-RNA/DNA/ protein isolation reagent $5(1 \mathrm{ml} / 100 \mathrm{mg}$ of tissue $)$ according to the manufacturer's protocol (Sigma Chemical Co.). The integrity of the RNA was verified by ethidium-bromide staining, and its concentration was determined spectrophotometrically.

Intestinal mucin genes and Brush-border enzyme mRNA analysis. RT-PCR was carried out with primers for two types of mucin genes: MUC2 and MUC3. MUC2 primers were designed from the fragment of Rattus norvegicus mucin mRNA (GI 506641): 5'-CAGAGTGCATCAGTGGCTGT-3' (forward); 5'-CCCGTCGAAGGTGATGTAGT-3' (reverse), and MUC3 primers from the MUC3 mRNA (GI 2589171): 5'-AACTGCGACTGGGGCACCCAGAAA-3' (forward); 5'AAAACCGTTTTTGTGTTAGTAT-3' (reverse).

BBM-enzyme mRNA expression was examined using RT-PCR with primers for aminopeptidase (AP) designed from the fragment of Rattus norvegicus mRNA for aminopeptidase (GI 8347065) 5'-AAGGTGGCAACAAGAAAGTGG-3' (forward); 5'-GAGCTGGCCCATCAGTGGTT-3' (reverse), and primers for sucrase isomaltase (SI) from the $R$. norvegicus sucrase-isomaltase mRNA fragment (GI 6981535): 5'-TAAG ATGGCAAAGAAGAAGTTCA-3' (forward); 5'-GCAACA ACAAGGTCTTGTGTGAT-3' (reverse). B-actin was used as the housekeeping gene, chosen and designed from the $\beta$-actin mRNA (GI 42475962): 5'-AACTGGGACGATATGGAGA AGATTT-3' (forward); 5'-TGGGCACAGTGTGGGTGA-3' (reverse).

Total-RNA was amplified using the Promega Access RTPCR System (Promega, Madison, USA). The program was as follows: $30 \mathrm{sec}$ at $94^{\circ} \mathrm{C}, 1 \mathrm{~min}$ at $60^{\circ} \mathrm{C}, 30 \mathrm{sec}$ at $68^{\circ} \mathrm{C}$ for 35 cycles, followed by $7 \mathrm{~min}$ at $68^{\circ} \mathrm{C}$. The RT-PCR products were examined on a $2 \%$ agarose gel, and visualized by staining with ethidium bromide.

The PCR was run with different numbers of cycles $(25$, $30,35,40,45$ or 50 ) for each primer set in order to find the center of the exponential increase in PCR products.

BBM-enzyme activity. Enzyme activities were assayed using jejunal, ileal and colonal lysates (250 mg tissue/5 $\mathrm{ml}$ of $50 \mathrm{mM}$ sodium phosphate buffer, $\mathrm{pH}$ 7.2). Maltase (EC 3.2.1.20) activity was assayed colorimetrically using maltose as a substrate (23), and expressed as millimoles glucose released per minute per gram of jejunal protein. LAP activity (LAP; EC 3.4.11.1) was determined by hydrolysis of $l$-leucine- $p$ nitroanilide for $15 \mathrm{~min}$ at $37^{\circ} \mathrm{C}$, and $p$-nitroanilide was determined spectrophotometrically at $405 \mathrm{~nm}$ according to Benajiba and Maroux (24). One unit of LAP activity was defined as the production of $1 \mu \mathrm{mol} p$-nitroanilide per minute per gram of jejunal, ileal or colonal protein. Total protein was determined using the Bio-Rad protein assay (Bio-Rad Laboratories, Hercules, CA).

Morphological examination. Fresh sections of colon, ileum and jejunum tissue were obtained from the same areas of the large and small intestines of all rats in the two groups $24 \mathrm{~h}$ after colitis induction. Intestinal segments were fixed in $4 \%(\mathrm{v} / \mathrm{v})$ buffered formaldehyde, dehydrated, cleared and embedded in paraffin. Serial sections were cut at $5 \mu \mathrm{m}$, deparaffinized in xylene, rehydrated and stained with hematoxylin and eosin. Sections were examined by light microscopy. 

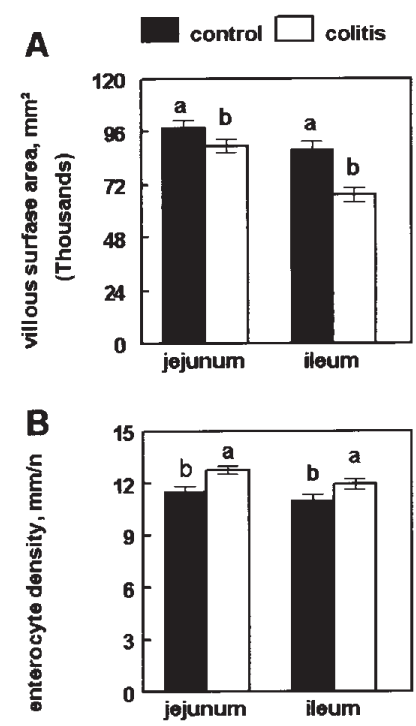

Figure 1. Effect of colitis induction on rat small intestinal villous surface area (A), and enterocyte density (B).Values are means \pm SEM, $n=4$. Small intestinal segment. The means without a common letter differ, $\mathrm{P}<0.05$.

Measurements. Villus surface area was calculated from villus height and width at half the height. Goblet-cell area was calculated from the length and width of the goblet cell 'cup' in cross-sections of the villi. The long diameter of the cup was defined as the distance between the cell's luminal opening and site of constriction, the short diameter was determined at the mid-point of the long diameter, and the elliptical area was calculated. Goblet-cell density was calculated as the number of goblet cells per unit of surface area $\left(\mathrm{mm}^{2}\right)$. All measurements were performed with an Olympus light microscope using Epix XCAP software.

Statistical analysis. Values are presented as means \pm SEM. Treatment effects were analyzed using Student's t-test, carried out within segments but not between them. A post-hoc test (Tukey-Kramer) was performed when the interaction between treat-ments was significant. Differences were considered significant at $\mathrm{P}<0.05$. JMP version 5.1 (25) was used for all analyses.

\section{Results}

Macroscopic assessment of colon damage. Colitis induced by intrarectal administration of TNBS resulted in macroscopic damage associated with diarrhea, shortening and thickening of the colon, and mucosal ulceration.

Morphometric measurements. TNBS induction led to morphometric changes in the jejunal and ileal mucosa. Induction of colitis decreased villus surface area in both the jejunum and ileum by 8.7 and $23 \%$, respectively, relative to controls $(\mathrm{P}<0.05)$ (Fig. 1A). Enterocyte density increased significantly in both segments (by $10 \%$ in the jejunum, $8 \%$ in the ileum) (Fig. 1B).

Goblet-cell size was greater in the TNBS-induced jejunum than in the control group (Fig. 2A and Fig. 3). The area of the goblet cell containing the mucin granules increased by $26.5 \%$.

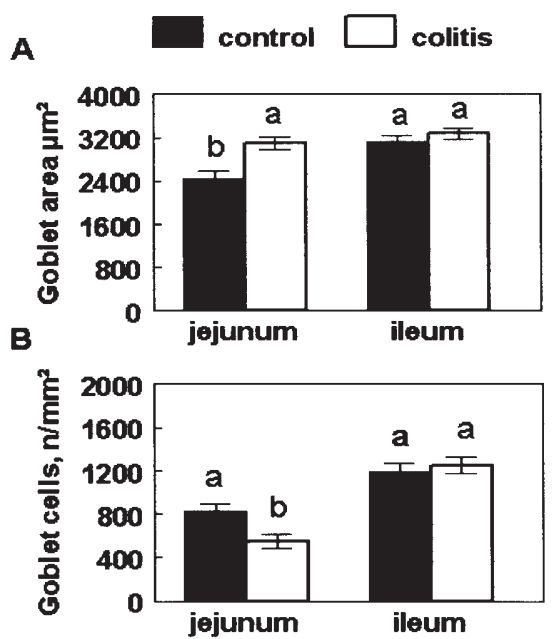

Figure 2. Effect of colitis induction on rat small intestinal goblet cells volume (A), goblet cell density (B). Values are means \pm SEM, $n=4$. Small intestinal segment. The means without a common letter differ, $\mathrm{P}<0.05$.
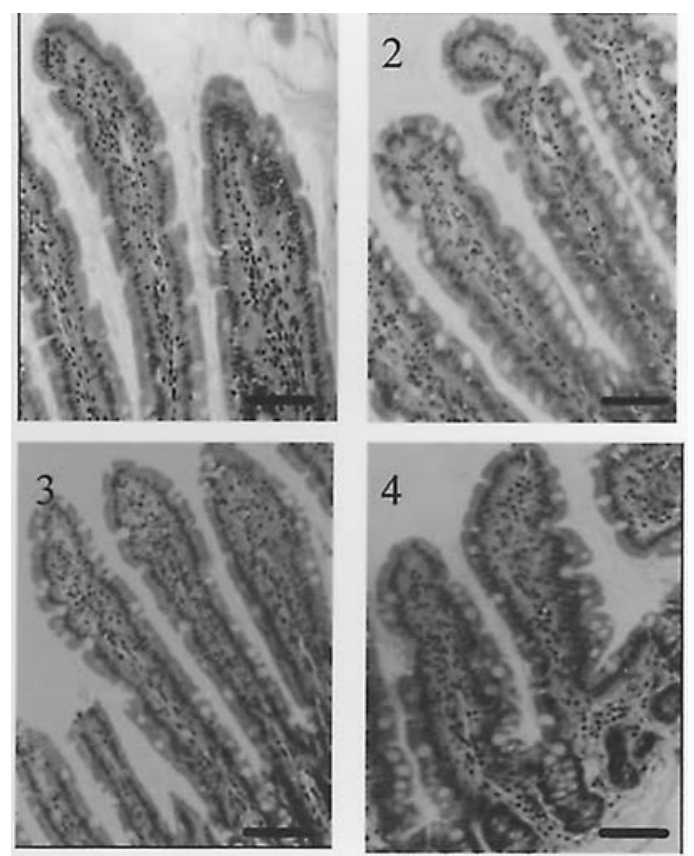

Figure 3. Effect of TNBS colitis on rat's small intestinal goblet cell size. Representative light micrographs of control and colitis jejunum $(1,2)$ and ileum $(3,4)$ stained with H\&E. Magnification x 100; bar, $50 \mu \mathrm{m}$.

The number of goblet cells per area decreased by $34 \%$ in the jejunum (Fig. 2B) following TNBS induction. However, no differences in goblet-cell density or volume were observed in the ileum.

BBM-enzyme expression in the jejunum, ileum and colon. Induction of TNBS colitis only resulted in different BBMenzyme expressions in the ileum. AP and SI mRNA expression decreased in the ileum of the TNBS-induced group compared to controls. AP expression descended by $79 \%$ (Fig. 4) and SI expression descended by $64 \%$ (Fig. 5). No significant differences in SI or LAP enzyme mRNA expression was found between control and TNBS-induced rat jejunums. As expected, 
A

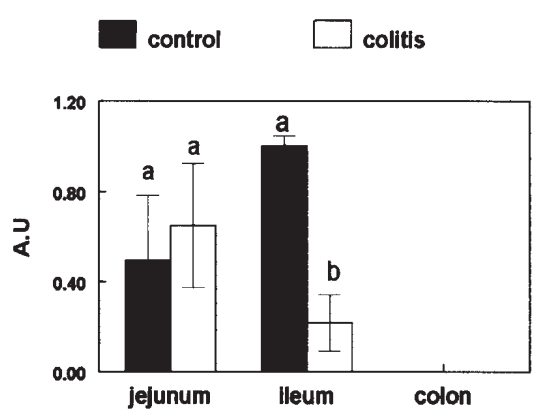

B

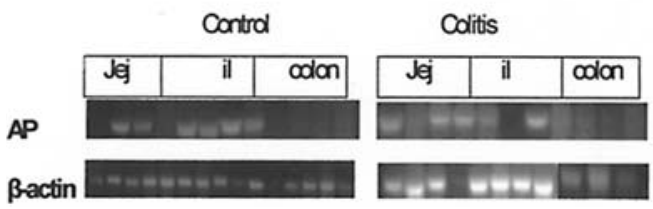

Figure 4. The effect of TNBS colitis induction on rat aminopeptidase mRNA expression (A). Changes in AP mRNA expression were measured by semiquantitative RT-PCR, and expression of $\beta$-actin was used as a housekeeping gene. Values are means \pm SEM, $n=4$. Means without a common letter differ, $\mathrm{P}<0.05$. (B), Representative RT-PCR product of aminopeptidase and $\beta$-actin mRNA expression in the intestine of the control and colitis rat.

A

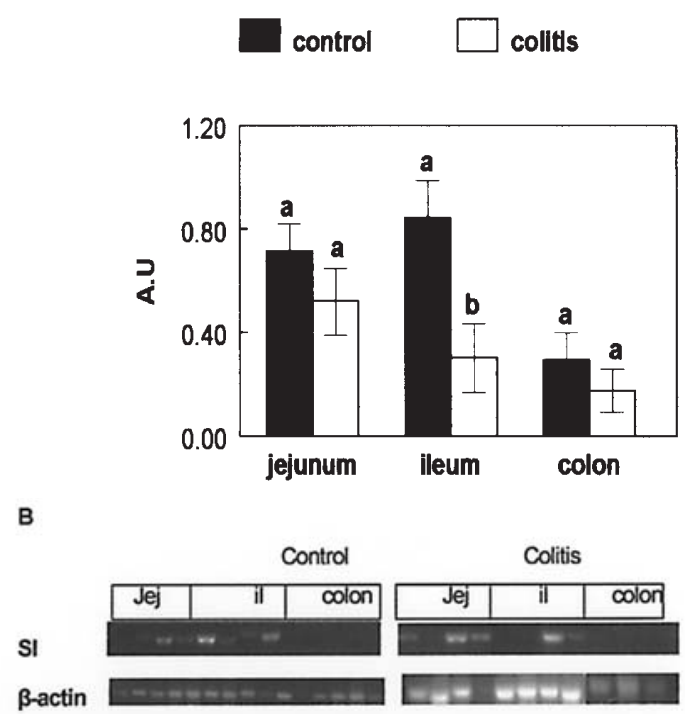

Figure 5. The effect of TNBS colitis induction on rat sucrase iso-maltase mRNA expression (A). Changes in SI mRNA expression were measured by semi-quantitative RT-PCR, and expression of B-actin was used as a housekeeping gene. Values are means \pm SEM, $n=4$. The means without a common letter differ, $\mathrm{P}<0.05$. (B), Representative RT-PCR product of sucrase isomaltase and $\beta$-actin mRNA expression in the intestine of the control and colitis rat.

SI and AP mRNA expression was minimal to undetectable in the colon.

Biochemical activity of the BBM enzymes. Lower levels of aminopeptidase (LAP) biochemical activity were detected in

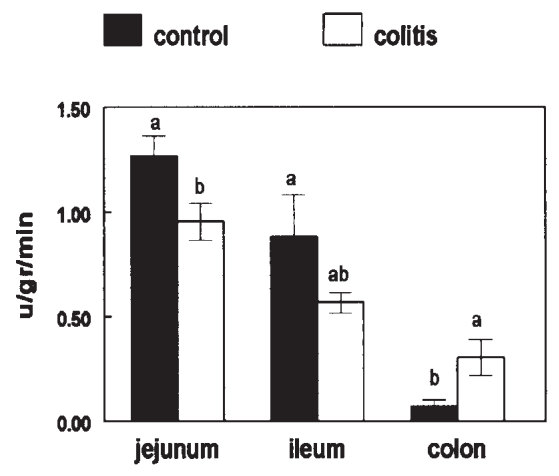

Figure 6. Effect of TNBS colitis on biochemical activity of the brush-border enzymes aminopeptidase in rat intestine. Values are means \pm SEM, $n=5$. The means without a common letter differ, $\mathrm{P}<0.05$.

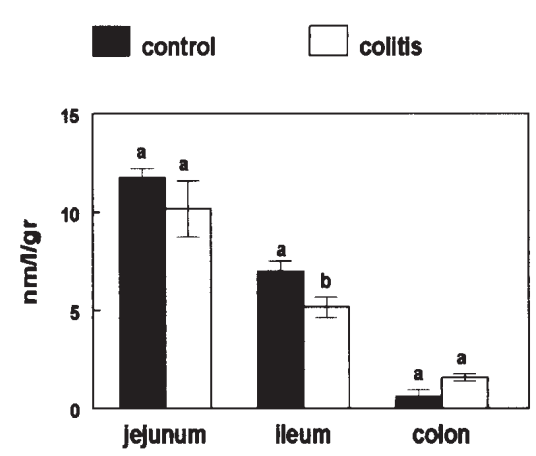

Figure 7. Biochemical activity of sucrase iso-maltase in control and TNBS colitis rats. SI activity was measured as its ability to digest maltose. Values are means \pm SEM, $n=5$. The means without a common letter differ, $\mathrm{P}<0.05$.

the jejunum of TNBS-induced rats and no significant differences were found in the ileum (Fig. 6), whereas sucrase isomaltase (SI) showed a similar pattern of biochemical activity in the jejunum of TNBS-induced rats and controls, and lower levels in the TNBS-induced ileum (Fig. 7).

Expression of mucin genes. A comparison of mucin mRNA expression relative to $B$-actin showed a decrease in MUC2 mRNA expression, following TNBS induction of colitis, in the jejunum and ileum, by $61 \%$ relative to controls, whereas in the colon the reduction was $74 \%$ ( $\mathrm{P}<0.05$ for all segments) (Fig. 8). In contrast, TNBS induction of colitis increased the expression of MUC3 mRNA in all three segments relative to controls: by $23 \%$ in the jejunum, almost $100 \%$ in the ileum, and $54 \%$ in the colon (Fig. 9).

\section{Discussion}

In this study we demonstrate the changes that occur in the rat ileum and jejunum after induction of TNBS colitis. This induction not only affected the colon, but also the small intestine's function by decreasing the villus surface area, reducing the number of goblet cells and increasing their size. A reduction in BBM-enzyme activity and RNA expression, as well as an alteration in mucin expression in the jejunum and ileum, were also observed.

Changes were detected in both immunopathology and gene expression. The inflammation classically associated 


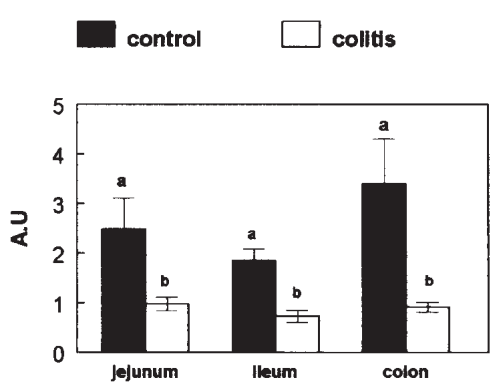

B

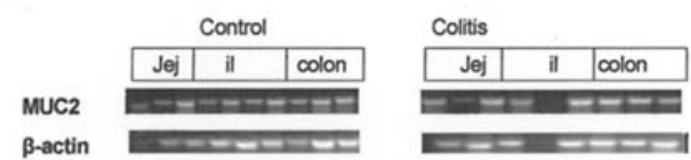

Figure 8. The effect of TNBS colitis induction on rat intestinal MUC2 mRNA expressions. (A), Changes in mucin mRNA expression were measured by semi-quantitative RT-PCR, and expression of $B$-actin was used as a housekeeping gene. Values are means \pm SEM, $n=4$. The means without a common letter differ, $\mathrm{P}<0.05$. (B), Representative RT-PCR product of intestinal MUC2 and $B$-actin mRNA expression in the colon of the control and colitis rat.

A
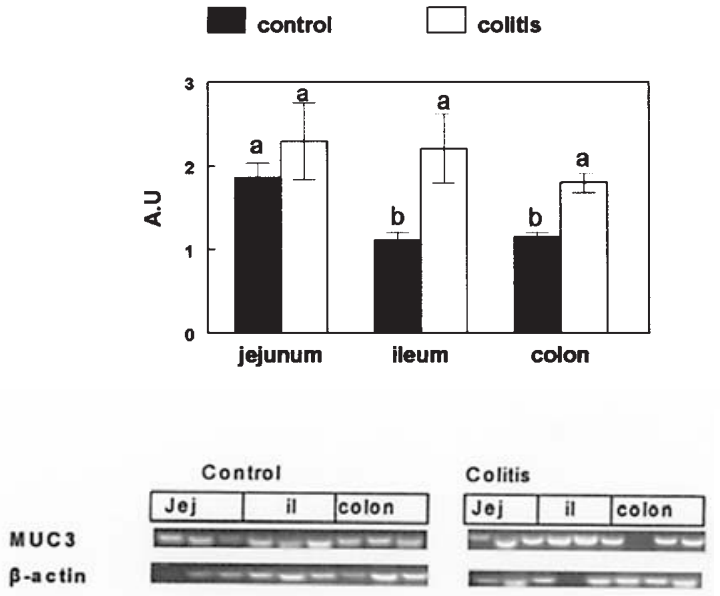

Figure 9. The effect of TNBS colitis induction on rat intestinal MUC3 mRNA expressions. (A), Changes in mucin mRNA expression were measured by semi-quantitative RT-PCR, and expression of $\beta$-actin was used as a housekeeping gene. Values are means \pm SEM, $n=4$. The means without a common letter differ, $\mathrm{P}<05$. (B), Representative RT-PCR product of intestinal MUC3 and $\beta$-actin mRNA expression in the colon of the control and colitis rat.

with UC is thought to involve only the colon; furthermore, if and when inflammation is noted in the small intestine, it is not thought to have any clinical or pathological significance. Schmidt et al (26) suggested that ileal inflammation is an independent variable, which is not strongly correlated with the severity or extent of disease in the colon, but in the extreme state of colonic involvement, ileal inflammation is often present. Proximal small bowel involvement is not a traditional feature of UC. There are only a few case reports of patients with histologically documented UC associated with upper small intestinal involvement in humans $(7,27,28)$. However, it is evident from our study that the inflammatory changes occurring in both the colon and the distal part of the small intestine reflect similar changes, all evolving from TNBS induction of colitis.

The primary function of the small intestine is to absorb nutrients. However, the intestinal epithelium is a critical interface between the environment and the organism. Clinical and laboratory studies in humans with IBD have long suggested that genetic and environmental factors play a fundamental role in the pathogenesis of this disorder. Recent immunological studies of the disease in humans and animals have focused attention on the possibility that IBD is due to a disregulated mucosal immune response to one or more unknown antigens $(1,29-31)$.

The complex system which protects the host from potentially harmful pathogens is often termed the 'gastrointestinal mucosal barrier'. This system comprises an immunological network termed the gut-associated lymphoid tissue that orchestrates molecular responses between immune cells and other components of the mucosal barrier (32).

The structural element of mucus that covers the mucosa of the GI is formed by mucins. GI mucins are the first line of host defense against enteric pathogens (33); thus mucus forms a protective layer against physiological, chemical and biological stresses.

IBDs are known to alter the expression of mucins throughout the colon (10,34-36). Alterations in mucin expression may play a role in the pathogenesis of IBD (34-37). Once the mucus barrier is breached, invasion occurs, and the invading pathogens gain access to the intestinal epithelium, causing depletion of the mucus layer. The host response to pathogen invasion may involve an alteration in mucin glycosylation (33).

A clear correlation between MUC and UC was presented by Kyo et al (38), who reported that individuals carrying one or two rare alleles of MUC3 (now MUC3A), which have an unusual number of 51-bp repeat units, are at increased risk for UC.

In the present study, we examined the expression of two types of mucin (MUC2 and MUC3). A decrease in MUC2 expression was displayed throughout the TNBS-rat intestine, concomitant with an increase in MUC3 expression. The MUC2 gene is expressed solely in goblet cells in the small and large intestine, whereas the gene encoding MUC3 is expressed in both goblet cells and enterocytes (39). Damage to the goblet cells' secretion mechanism may occur and cause a reduction in the expression of MUC2, which is a gel-forming type of mucin. Changes in MUC3 expression may be caused by altered mucin types in inflammation or by an increase in enterocyte density. MUC3 is a membrane-bound mucin and is not secreted, and as such is not affected by the goblet cells' secretion mechanism.

The decrease in MUC2 mRNA expression was not correlated to goblet-cell number or area. The results show inconsistent changes in goblet-cell number in the jejunum and ileum.

It should be noted that although the most significant decrease was observed in the ileum, no changes in goblet-cell area or number were found in related areas. A previous study of TNBS-induced colitis in the rat colon demonstrated an 
increase in the number and size of goblet cells in the crypts. The increased number of cells was suggested to reflect increased proliferation as a tissue-repair mechanism in response to TNBS (22).

TNBS induction might also affect epithelial cell function. Therefore, we examined the effects of TNBS-induced colitis on enterocyte-specific BBM-enzyme expression and activity. Our findings indicate that sucrase iso-maltase and aminopeptidase mRNA expression and biochemical activity decrease in the ileum of TNBS-induced rats. These data suggest that specific enterocyte function is down-regulated in the ileum following TNBS induction.

Enterocytes, apart from their participation in the digestive processes, perform more than a passive barrier function, and are often directly involved in the immune processes (40). BBMenzyme activities are an important characteristic of normal intestinal epithelial function as they are specific for enterocytes and the development of the BBM region, with its digestive and absorptive functions (14-16).

The results indicate that TNBS-induced colitis influences not only the rat colon, but also the distal part of its small intestine. However, it appears that the inflammatory response of the rat ileum to TNBS differs from that of its jejunum. Most of our results indicate that the effect of TNBS-induced colitis on ileal mucosal function is the same or greater than that on the jejunum. Nevertheless, even though the ileum is closer to the induced area, and hence expected to be more affected, jejunal goblet cells display more significant changes than ileum cells. This finding may be explained by different mechanisms influencing goblet-cell and enterocyte function. Further studies are needed to understand this outcome.

Our findings suggest that the small intestine's reaction to TNBS-induced colitis may be a result of a systemic response of the mucosal immune system to inflammation of the colon.

\section{References}

1. Claesson MH, Bregenholt S, Bonhagen K, Thoma S, Moller P, Grusby MJ, Leithauser F, Nissen MH and Reimann J: Colitisinducing potency of $\mathrm{CD} 4^{+} \mathrm{T}$ cells in immunodeficient, adoptive hosts depends on their state of activation, IL-12 responsiveness, and CD45RB surface phenotype. J Immunol 162: 3702-3710, 1999.

2. Podolsky DK: Inflammatory bowel disease. N Engl J Med 347: 417-429, 2002.

3. Fiocchi C: Inflammatory bowel disease: etiology and pathogenesis. Gastroenterology 115: 182-205, 1998.

4. Aube AC, Cherbut C, Barbier M, Xing JH, Roze C and Galmiche JP: Altered myoelectrical activity in non-inflamed ileum of rats with colitis induced by trinitrobenzene sulphonic acid. Neurogastroenterol Motil 11: 55-62, 1999.

5. Morris GP, Beck PL, Herridge MS, Depew WT, Szewczuk MR and Wallace JL: Hapten-induced model of chronic inflammation and ulceration in the rat colon. Gastroenterology 96: 795-803, 1989.

6. Tamaki Y, Steven M, Robert D and Matthew B: A comparative analysis of two models of colitis in rats. Gastroenterology 102: 1524-1534, 1992.

7. Valdez R, Appelman HD, Bronner MP and Greenson JK: Diffuse duodenitis associated with ulcerative colitis. Am J Surg Pathol 24: 1407-1413, 2000.

8. Haskell H, Andrews CW Jr, Reddy SI, Dendrinos K, Farraye FA, Stucchi AF, Becker JM and Odze RD: Pathologic features and clinical significance of 'backwash' ileitis in ulcerative colitis. Am J Surg Pathol 29: 1472-1481, 2005.

9. Yantiss RK, Sapp HL, Farraye FA, El-Zammar O, O'Brien MJ, Fruin AB, Stucchi AF, Brien TP, Becker JM and Odze RD: Histologic predictors of pouchitis in patients with chronic ulcerative colitis. Am J Surg Pathol 28: 999-1006, 2004.
10. Rhodes JM: Mucins and inflammatory bowel disease. Qjm 90: 79-82, 1997.

11. Rowland I and Malett A: The influence of dietary fiber on microbial enzyme activity in the gut. In: Dietary Fiber: Chemistry, Physiology and Health Effects. Kritchevsky D, Bonfield C and Anderson J (eds). Plenum, New York, pp195-206, 1990.

12. Forstner J, Oliver M and Sylvester F: Production, structure and biologic relevance of gastrointestinal mucins. In: Infections of the Gastrointestinal Tract. Blaser M, Smith P, Ravdin J, Greenberg H and Guerrant R (eds). Raven Press, New York, pp71-88, 1995.

13. Lehky P, Lisowski J, Wolf DP, Wacker H and Stein EA: Pig kidney particulate aminopeptidase. A zinc metalloenzyme. Biochim Biophys Acta 321: 274-281, 1973.

14. Semenza G: Anchoring and biosynthesis of stalked brush border membrane proteins: glycosidases and peptidases of enterocytes and renal tubuli. Annu Rev Cell Biol 2: 255-313, 1986.

15. Ferraris RP, Villenas SA and Diamond J: Regulation of brushborder enzyme activities and enterocyte migration rates in mouse small intestine. Am J Physiol 262: G1047-G1059, 1992.

16. Weiser MM: Intestinal epithelial cell surface membrane glycoprotein synthesis. I. An indicator of cellular differentiation. J Biol Chem 248: 2536-2541, 1973.

17. Semenza G: Mode of insertion of the sucrase-isomaltase complex in the intestinal brush border membrane: implications for the biosynthesis of this stalked intrinsic membrane protein. Ciba Found Symp: 133-146, 1979.

18. Spiess M, Brunner J and Semenza G: Hydrophobic labeling, isolation and partial characterization of the NH2-terminal membranous segment of sucrase-isomaltase complex. J Biol Chem 257: 2370-2377, 1982.

19. Kessler M, Acuto O, Storelli C, Murer H, Muller M and Semenza G: A modified procedure for the rapid preparation of efficiently transporting vesicles from small intestinal brush border membranes. Their use in investigating some properties of D-glucose and choline transport systems. Biochim Biophys Acta 506: 136-154, 1978

20. Kenny AJ and Maroux S: Topology of microvillar membrance hydrolases of kidney and intestine. Physiol Rev 62: 91-128, 1982

21. Hayashi T, Ishida T, Motoya S, Itoh F, Takahashi T, Hinoda Y and Imai K: Mucins and immune reactions to mucins in ulcerative colitis. Digestion 63 (Suppl. 1): S28-S31, 2001.

22. Torres MI, Garcia-Martin M, Fernandez MI, Nieto N, Gil A and Rios A: Experimental colitis induced by trinitrobenzenesulfonic acid: an ultrastructural and histochemical study. Dig Dis Sci 44: 2523-2529, 1999.

23. Dahlquist A: Method of assay of intestinal disaccaridases. Anal Biochem 7: 18-25, 1964.

24. Benajiba A and Maroux S: Purification and characterization of an aminopeptidase A from hog intestinal brush-border membrane. Eur J Biochem 107: 381-388, 1980.

25. SAS Institute Inc: JMP User's Guide, Version 5.1, 2003.

26. Schmidt CM, Lazenby AJ, Hendrickson RJ and Sitzmann JV: Preoperative terminal ileal and colonic resection histopathology predicts risk of pouchitis in patients after ileoanal pull-through procedure. Ann Surg 227: 654-662, 1998.

27. Mitomi H, Atari E, Uesugi H, Nishiyama Y, Igarashi M, Arai N, Ihara A and Okayasu I: Distinctive diffuse duodenitis associated with ulcerative colitis. Dig Dis Sci 42: 684-693, 1997.

28. Sasaki M, Okada K, Koyama S, Yoshioka U, Inoue H, Fujiyama Y and Bamba T: Ulcerative colitis complicated by gastroduodenal lesions. J Gastroenterol 31: 585-589, 1996.

29. Mackay F, Browning JL, Lawton P, Shah SA, Comiskey M, Bhan AK, Mizoguchi E, Terhorst C and Simpson SJ: Both the lymphotoxin and tumor necrosis factor pathways are involved in experimental murine models of colitis. Gastroenterology 115: 1464-1475, 1998

30. Brandtzaeg P, Haraldsen G and Rugtveit J: Immunopathology of human inflammatory bowel disease. Springer Semin Immunopathol 18: 555-589, 1997.

31. Mizoguchi A, Mizoguchi E, Smith RN, Preffer FI and Bhan AK: Suppressive role of B cells in chronic colitis of T cell receptor alpha mutant mice. J Exp Med 186: 1749-1756, 1997.

32. Acheson DW and Luccioli S: Microbial-gut interactions in health and disease. Mucosal immune responses. Best Pract Res Clin Gastroenterol 18: 387-404, 2004.

33. Moncada DM, Kammanadiminti SJ and Chadee K: Mucin and Toll-like receptors in host defense against intestinal parasites. Trends Parasitol 19: 305-311, 2003. 
34. Smithson JE, Campbell A, Andrews JM, Milton JD, Pigott R and Jewell DP: Altered expression of mucins throughout the colon in ulcerative colitis. Gut 40: 234-240, 1997.

35. Podolsky DK and Isselbacher KJ: Composition of human colonic mucin. Selective alteration in inflammatory bowel disease. J Clin Invest 72: 142-153, 1983.

36. Podolsky DK and Isselbacher KJ: Glycoprotein composition of colonic mucosa. Specific alterations in ulcerative colitis. Gastroenterology 87: 991-998, 1984.

37. Shaoul R, Okada Y, Cutz E and Marcon MA: Colonic expression of MUC2, MUC5AC and TFF1 in inflammatory bowel disease in children. J Pediatr Gastroenterol Nutr 38: 488-493, 2004.
38. Kyo K, Parkes M, Takei Y, Nishimori H, Vyas P, Satsangi J, Simmons J, Nagawa H, Baba S, Jewell D, Muto T, Lathrop GM and Nakamura Y: Association of ulcerative colitis with rare VNTR alleles of the human intestinal mucin gene, MUC3. Hum Mol Genet 8: 307-311, 1999.

39. Chang SK, Dohrman AF, Basbaum CB, Ho SB, Tsuda T, Toribara NW, Gum JR and Kim YS: Localization of mucin (MUC2 and MUC3) messenger RNA and peptide expression in human normal intestine and colon cancer. Gastroenterology 107: 28-36, 1994.

40. Snoeck V, Goddeeris B and Cox E: The role of enterocytes in the intestinal barrier function and antigen uptake. Microbes Infect 7: 997-1004, 2005. 